\title{
Family Function Deficiency and the Substitution Model for the Underage Children of Female Prisoners -an Exploration of 100 Example Cases of Women's Prison in L Province
}

\author{
Xizheng Shan \\ Lake Country Lutheran High School, Wisconsin 53029, US \\ hljshanxizheng@163.com
}

\begin{abstract}
Through the investigation of 100 female prisoners and their families and children, I found that the underage children of prisoners are generally surrounded by factors such as a lack of care, parent-child isolation, difficulties in life, etc., which result in psychological difficulties, emotional inferiority, peer's exclusion, lack of self-confidence or sense of cooperation, as well as communication challenges. Some underage children have problems such as prematurely dropping out of school, surviving around the bottom of society, or repeating the mistakes of their mothers by taking the criminal path. There are still a small number of people who can overcome difficulties and achieve normal socialization. Through the comparative analysis of these two groups, I found that the underage children of the female prisoners can be socialized normally. It is derived from two alternative modes: First is through the input and reinforcement of kinship, integrate the internal relationship resources of the family, and realize such kinship network to replace the parent-child relationship through the "functional transformation" of relationships. Second, the social support of social organizations replaces and supplements the missing family functions. Therefore, we must integrate social resources, mobilize social forces, and rebuild social support network for underage children of female offenders through "functional replacement" within and outside the family.
\end{abstract}

Keywords: female offenders; minor children; family function deficiency; functional replacement.

\section{Introduction}

At present, the number of female prisoners in China is increasing year by year. In the past 10 years, it has increased by $46 \%$. By the end of 2015 , the number of criminals serving prison sentences in China alone was close to 1.7 million, and the number of female prisoners accounted for $6.3 \%$ of the total number of prisoners. Along with this, the number of underage children of prisoners has risen rapidly, approaching more than 750,000 [1]. This group has become a special vulnerable group in society and has received much attention from the society. The author has established a voluntary public welfare website, the Bean Sprouts website, which specializes in exposing and addressing the issue of "left-behind children" in China. In the process of public welfare service, it has reached out to a special group of left-behind children. They are the more vulnerable group of children: the children of female detainees.

The female prisoners, that is, the female prisoners in prison, are the mothers of these said children. They are the main members of the family raising children and take on more responsibility for caring for and educating underage children. When these women are sentenced to prison for crimes, their imprisonmen leads directly to the poor living situation for their their children. The difficult situation and the contradiction of reality have caused great harm to the physical and mental health of these underage children, which has led to obstacles to their socialization, and even went astray and embarked on the path of crime. I investigated 100 female criminals in the L Provincial Women's Prison. On the premise of obtaining the consent of the female prisoner, I not only obtained research materials and information, but also helped formed groups among the minors so they can help each other. This article will make a rational analysis of the obstacles of underage children who serve prisoners, and propose corresponding intervention strategies from the social work's point of view. 


\section{Family Function Deficiency and the Actual Predicament of the Underage Children of Female Prisoners}

In the L Provincial Women's Prison, 3,780 female prisoners were detained. According to the research needs, the author took 100 female prisoners by simple random sampling and conducted questionnaire surveys and in-depth interviews. Their age distribution is as follows:

Table 1. Age distribution table of female prisoners interviewed

\begin{tabular}{c|c|c|c|c}
\hline Age & 50 year old and above & $40-49$ years old & $30-39$ years old & 29 year old and below \\
\hline Number & 15 & 46 & 31 & 8 \\
\hline
\end{tabular}

As seen from the table above, the vast majority of female prisoners are women of marriage and childbearing age, and they are essentially at the peak of their lives. Their children are very young, so they need the care and warmth of maternal love, which means their mothers' imprisonment cause their great sufferance from the separation of mother and child. The parents of these female prisoners also entered the older age with reduced physical strength and energy. It is therefore difficult for them to take care of their grandchildren.

Table 2. Distribution of crime types of female prisoners interviewed

\begin{tabular}{c|c|c|c|c|c}
\hline $\begin{array}{c}\text { Types of } \\
\text { Crimes }\end{array}$ & $\begin{array}{c}\text { Drug-related } \\
\text { Crimes }\end{array}$ & $\begin{array}{c}\text { Violence-related } \\
\text { Crimes }\end{array}$ & $\begin{array}{c}\text { Property } \\
\text { Infringement }\end{array}$ & $\begin{array}{c}\text { Duty } \\
\text { Crimes }\end{array}$ & $\begin{array}{c}\text { Sex } \\
\text { Crimes }\end{array}$ \\
\hline Number & 37 & 22 & 33 & 6 & 2 \\
\hline
\end{tabular}

From the table above, we can see that the female criminals interviewed are mostly involved in drugs, financial and violent crimes. In violent crimes, they often commit the felony of intentional homicide and intentional injury. In general, most female prisoners are engaged in criminal activities such as drug trafficking, fraud, corruption, bribery, prostitution, and theft.

Table 3. Distribution of female prisoner who has children

\begin{tabular}{c|c|c|c|}
\hline Whether you have children & No Children & Have Children & Underage Children \\
\hline Number & 4 & 96 & 69 \\
\hline
\end{tabular}

Of the 100 female prisoners who were investigated, 96 female offenders had children. Of these female prisoners with children, 55 are divorced. For these divorced female offenders, if the child follows the life of the female prisoner, the daily care can only be taken charge by the grandparents, and their dedication and willingness only solve part of the problem. If the child follows the father's life after the divorce, the child is practically taken away from the female prisoner. The relationship is broken and the child's maternal love is seriously missing. According to the author's investigation, for children who live with their fathers, regardless of whether their parents' marriage relationship is broken, their fathers are often busy with work and socialization, and it is thus difficult for them to take good care of their children. In daily life, they often put their children in grandparents' place and are hosted and cared for by the elderly at home. In the family, the elderly become the main interactive subject of the child.

Regarding the above-mentioned female prisoners with children, 69 children are minors. Among these underage children, 32 live with their fathers, 21 underage children live with grandparents, and the rest of the minors live with relatives, teachers and others. One mother, Yang, is 42 years old and has a 9-year-old girl. Based on my interview with her, she said: "Children and fathers work for me and my children in the hometown. The children live with their grandparents, but her grandparents are fine to take care of food and clothing but they cannot help her with academic work. There is not much communication [between the two generations]." For the underage children of female prisoners, the basic needs of eating and drinking are basically guaranteed, but there is a great shortage of spiritual 
comfort and family education, which makes the socialization process of many underage children incomplete. .

Among the 69 people with minor children, 27 female prisoners from the "double criminal" family, that is, husband and wife, father and daughter, mother and child, two brothers or two or more are prison detainees [2]. Within such a broken and fragile family environment, the growth and socialization process of underage children can only be imagined. They are not only in lack of material conditions, but also in basic care and education. They are in a state of both material and spiritual deficiency, so the child's healthy growth is impossible.

For the families of female prisoners who are serving their sentences, they generally have difficulties in terms of both living and financial situations. According to the author's survey, $34 \%$ of the main economic sources of female children's life come from the father's income; $25 \%$ of the children are assisted by relatives and friends; $11 \%$ of the minor children rely on the minimum living security, civil affairs and supporting government relief channels; $13 \%$ of underage children are supported by social donations and public welfare; $17 \%$ of underage children have no source of income. For these female offenders, most of them can barely maintain their lives, so their economic situation is very worrisome.

The victim, Zhao, said: "I have three children: the eldest son is 17 years old, the two daughters are twins, 11 years old, and the burden of life is indeed heavier. Just because I want to make more money, I have gone to the criminal route of trafficking drugs. Now that I am sentenced in prison, the lives of my family are even more difficult." After they are in prison, the family's economic situation will worsen. Ordinary left-behind children will get the money earned by their parents working outside the home. However, the underage children of the female prisoners can neither receive the care of the mother nor receive remittances sent by the mother from outside. Moreover, in order to visit the provincial capital cities, some family members spend a lot of extra expenses such as transportation, accommodation and other expenses, which makes the family economic situation of female prisoners even worse. Due to economic constraints, many family members of female offenders cannot or rarely visit, resulting in the separation of female offenders from the family. The situation is not promising for the educational reform of criminals, to say the least.

\section{The Impact of the Lack of Family Function on the Socialization of Underage Children of Female Prisoners}

It is not difficult to find that female prisoners have been imprisoned for crimes, causing a serious blow to their families, which not only damaged the original family structure, but also affected the normal operation of the family. The absence of a mother's role, the lack of family function, and the isolation of parent-child relationships have greatly hindered the socialization of underage children.

\subsection{Children's Psychological Inferiority and Autistic Personality}

Interviewee Wang said: "(My) child is underage. Because the mother's crime has caused harm to the child, she mentally and psychologically incapable of being like a child in a healthy family. The child lacks maternal love and has severe autism without the will to interact with the outside world." For minors, families and schools are the main places of social activity, and their socialization is mainly based on family and school education. However, underage children who serve female offenders are unable to obtain complete family relationships and normal schooling. Their families are incomplete. They have neither the care of their mothers nor the economic support. They cannot get the care and belongings that many of their peers have. In school, the comparison and disparity between the students also made them feel inferior, and they could not get a sense of belonging and self-identity in the peer group. Most of the women in custody interviewed believe that minor children need counselling in psychological and mental health. 


\subsection{Child's Peer Rejection and Social Difficulties}

The imprisonment of the mother, for many underage children, is like a label that can never be rid of, destroying their social network. Mothers who serve their sentences have broken families and often cause discrimination among peer groups and exclusion from neighborhoods. Chen, a child from the provincial capital, is very aware of her family's situation. She is uncomfortable with her classmates and teachers, and often skips school and abandons her studies. "Since my mother was locked up, my father went out to work. I lived with my grandfather. I have never eaten KFC, and my grandfather is doing some stew for me every day. I don't want to go when the class organizes activities. The teacher knows the situation of my family so she does not accept my money. That's why I do not want to go" (according to Chen's interview). The inability of families to provide effective support and control is an important social risk factor for juvenile delinquency [3]. Respondent Jiang (42 years old, daughter 14 years old) says, "I hope the children's teachers and classmates can give children more smiles and help."

Minor children cannot get the economic treatment of their peers, which causes their sense of inferiority. In the process of helping underage children of the women in custody, they really see that many children live in poverty and even have no food and clothing.

\subsection{Parent-child Isolation and a Lack of Family}

In L Province, there are 15 cities (including 2 provincial governing counties) and 21 prisons, but there is only one female prison. In this case, the road to visit is far away and becomes a major obstacle to the visit of female offenders, causing female offenders' meeting with their families extremely inaccessible. The survey shows that long commuting time and high cost of visits are the main reasons why many female prisoners cannot meet their children. Respondent Qin (36 years old, committed theft charge) and her daughter can see each other once a year. During the interview, she said: "From the place where I live to the prison, [in order to see me my family has to] take a train. During my child's winter vacation I can come once a year. I don't want to delay her study when she starts school." $\mathrm{L}$ province has a expansive terrain. For families living in remote rural areas, it takes three days to come to the provincial capital. Among the female prisoners interviewed, only $29 \%$ of the female prisoners in custody can have normal visits with their children to ensure the exchange and maintenance of family relationships; $40 \%$ of female prisoners can only communicate with their children through telephone; the remaining female prisoners and children have no contact with each other whatsoever.

In the L Provincial Women's Prison, among the female prisoners there are inter-provincial drug dealers in their hometowns in Guizhou, Hunan, and Zhejiang. Their visiting costs are even more unimaginable. Guizhou's detained female Li (43 years old, guilty of drug trafficking) was sentenced to 15 years in prison. "It has been closed for more than three years, and the family has not come (visited) once. I often meet my family in my dreams. The thoughts and loves of the loved ones and children can't be expressed in words. The most regrettable thing in my life is towards parents and children."

Some prisoner female offenders have broken their parent-child relationship due to a lack of contact with their children for a long time. Zhan (51-year-old, guilty of intentional assault) has been serving his sentence for almost five years. "I have never seen a child. The child lives with his grandmother. The child's dad lives outside and has another home. I especially miss the child. If possible, I want to know everything about him now."

Due to the high cost of visits and the imperfect system, the female prisoners and their children lack effective communication channels, and the parent-child relationship is in a state of alienation or even loss. According to the study, in prisons, the most concern enunciated about the children of prisoners is: "The child is left unattended; the child will suffer social discrimination; the child is sick; or the child does not go to school." From the perspective of serving female prisoners, the normal visits of underage children can eliminate the worry of their mother, and at the same time, the spiritual pillar of the rehabilitation of female prisoners; from the perspective of children, smooth and adequate visits 
can satisfy the needs of minor children. The parent-child relationship continues when the family can enjoy the warmth of their household.

\subsection{Dropping out of School and Taking Risks}

The level of education of female prisoners is generally low, and few have received college education. The survey shows that only female offenders with a small number of duty crimes have higher education. For most female prisoners, their own knowledge and ability reserves are insufficient, so they often hit the wall in employment. Most people do not have formal occupations. The influence of bad friends and the immediate interests drive them to take risks and fall into the abyss of crime. Therefore, I hope that children can study hard, work smoothly in the future, avoid repeating their own mistakes, and realize the simple wish of most female criminals. Respondent Li (who is 48 years old and is guilty of intentional assault, daughter 14 years old) said: "I hope that children can learn more, have a diploma, find a stable job, and earn more money." However, according to the statistics of the Ministry of Justice, $13.1 \%$ of the minor children of detained criminals dropped out early, of which $6.6 \%$ lived in large and medium-sized cities, $10.1 \%$ lived in small cities, counties and towns, living in rural areas. In more serious cases, the dropout rate reached $16.1 \%$.

The findings of this study also confirm the above situation. Among the 96 female prisoner families with children, most of the children dropped out of school after they graduated from junior high school. Some people entered the society after graduating from junior high school and less than $10 \%$ were able to read high school and university. The son of the respondent Chen ( 45 years old, who committed the crime of organizing prostitution) is 15 years old. After Chen was imprisoned, he was transferred to a truant school. After Chen and her husband divorced, she said, "I have never seen a child for many years, I want the government to help see if the child is growing healthily, and whether there are difficulties in life."

The survey shows that many minors are out of school after their parents are in prison. The interviewee Zhao (50 years old, committing illegal encroachment) is full of regrets for the children who drop out of school. She said, "I want to make money to study, and I will study hard in the future. Unfortunately, he does not want to study. After I was in prison, no one looked at him. He has been escaping from school. Even the teacher can't help. I don't want this student. I am very sad about this." Discrimination and exclusion by peer groups is the main reason why many children drop out of school. In this case, these children tend to find a sub-cultural group that can accept themselves and ignore their "tags" and seek comfort and sympathy in them, which is also the underlying reason why the offender's children are easy to embark on the criminal road [4].

\section{Functional Substitution and "Atypical Cases" of Underage Children's Socialization}

Sociology believes that family support is the foundation of family members' social life. On the one hand, the family is the basic place for family members to live, covering all aspects of family members' lives, and providing essential support for the healthy growth of family members. The material supply of the family, the cooperation in production, the care in life, the influence of education, the emotional support and the spiritual comfort can eliminate the tension brought by social life outside the family system by attenuating setbacks and social risks in regards to external challenges. On the other hand, the improvement of family life and the growth of family members are inseparable from the input and participation of all family members and the mutual support of family members. Only by establishing a harmonious family relationship for family members and providing the necessary family-based support can we meet the basic needs of family members and truly improve the social life of them.

For children, family is the first place for their socialization [5], which has become an important factor affecting their healthy growth. The family helps children to learn basic life skills and survival experience, to help them become familiar with basic interpersonal communication skills and life principles, and to improve their social adaptability. The behavioral learning of children and the interaction between family members are closely related. In particular, the communication between 
children and parents is an important factor affecting children's behavioral learning. When a child in a family has problems, it is impossible to get rid of the family system to accurately understand the child's problems. It may be a lack of family function to the individual [6]. Therefore, restoring family functions is of great significance for solving the problem of the client.

The underage children of female prisoners are growing up in the disabled family. The lack of parental isolation and the lack of family care make them lack the environment for growth and development. The absence of parental roles, especially the imprisonment of mothers, makes the protection, support and parenting functions of the original family seriously lacking, unable to meet the physical and mental health of the female offenders, and hinder the socialization of the children of female offenders. Through investigation and research, we can easily find that due to lack of guardianship and warmth, the children of prisoners have serious obstacles in life, interpersonal communication, mental health, self-identification skills, etc., which are prone to self-enclosure, ignorance, and premature absence. All these factors lead to physical and mental disorders and deviations such as smoking and drinking, accidental injuries, bad adolescents social circles and even crimes.

However, according to my investigation, there have been two atypical cases. When it comes to children of the female prisoners that are minors, although the family is incomplete, the parents are separated, and the maternal love is missing, but the adversity of rebirth, "uncharacteristic", on the road to socialization is quite smooth.

Case 1: Zhang is a 14-year-old boy who lives in M City, L Province, and is currently enrolled in middle school. The father is a car mechanic, the mother commits fraud and illegal encroachment, and is currently serving a sentence in the L Provincial Women's Prison. After the mother was in prison, Zhang's parents divorced. After the agreement, Zhang followed his mother's life. He is now living in a house of about 18 square meters with his grandfather and grandmother. The conditions are relatively shabby and the surrounding sanitation and security conditions are poor. There is a lack of a stable source of income in the family, relying only on the grandparents' pension and the small amount of living expenses given by the father. Because of the long-term and elder grandparents living together, Zhang's daily communication has encountered obstacles, and Zhang's education has become very difficult. Although Zhang and his parents rarely communicate, they interact frequently with aunts and uncles. They are very concerned about Zhang. From study and counseling to life care, they are more meticulous. They often talk to Zhang and accompany him on weekends to go out and play together. When Zhang listened to his uncle, he deeply regarded them as people who were dearer than their parents. According to Zhang's mother, Zhang is more self-disciplined, hard-working, diligent and economical, and has excellent academic performance. He has just won the first prize of the provincial physical competition and mathematics competition, which makes the family happy and assured.

Case 2: Xiao Zhao, female, 17 years old, dropped out of school early because her mother was in prison. She was once self-enclosed, reticent, and mixed with some idle youth. Last year, the "Bean Sprout" charity volunteer organization that I created set up a business platform and created employment opportunities for the children of prisoners. Xiao Zhao used the "Bean Sprout" link to form pairs with loved ones, founded a handicraft workshop, opened a Taobao shop, and learned some skills. Through the coordination of the "Bean Sprout" charity volunteer organization, Xiao Zhao applied for government subsidy and met with the mother who served her sentence in the L Provincial Women's Prison. She has a small agreement with her mother to give each other the biggest hug on the day the mother is released from prison. The regular meeting between the mother and the daughter allowed them to feel the warmth of the family again. At the same time, Xiao Zhao became a member of the "Bean Sprout" charity organization and actively participated in volunteer service activities to achieve self-worth and enhance self-efficacy. She has just been named a provincial excellent volunteer.

In both cases, the family structure was damaged due to the mother's imprisonment. The breach of the parent-child relationship and the lack of parental roles made the underage children lack adequate life care and necessary family education. However, what is unusual is that Zhang and Zhao in the case have overcome the reality of suffering and family adversity, and opened up a new path of 
development in a difficult living environment. In the first case, Zhang mainly relied on aunts and uncles. To a certain extent, their care, education and guidance both eased the daily life of Zhang and compensated for the lack of Zhang's parents' role. Zhang still can feel the warmth of life when his parents leave the scene. His recognition of his uncle and aunt continued the mourning of his mother's love, and his parent-child relationship gained an alternative development. The author believes that Zhang's smooth socialization stems from "functional substitution within the family." Through the input and strengthening of kinship, it integrates the relationship resources within the family, realizes the "functional transformation" of kinship relationship instead of parent-child relationship, and helps underage children to get rid of the real dilemma of parental loss and family damage.

In Case 2, Zhao's normal socialization stems from "functional substitution outside the home." Through the resource links and resource integration of social organizations, Xiao Zhao not only obtained government subsidies and employment opportunities, but also possessed a skill and network. With the support of social organizations, Xiao Zhao and his mother established a regular meeting system, and the isolated parent-child relationship was bridged and extended. By becoming a member of the non-profit organization, Xiao Zhao participates in volunteer service activities to reach out to the society and understand the society, realize self-worth and social value, and enhance the sense of identity and social belonging. In short, the social support of social organizations has replaced and supplemented the missing family functions to a certain extent, and has become an important guarantee for the socialization of underage children.

\section{The Dual Path of Social Support Reconstruction for Underage Children}

Social support is a social behavior in which the main body, such as government, community, family, and social organization, uses social networks and integrates social resources to provide material assistance and spiritual counseling to vulnerable groups [7]. Social support can improve the living conditions of the weak and improve their quality of life, thus promoting the harmony and stability of the entire social system. Social support involves not only formal assistance from government departments and professionals, but also informal help from families, friends, colleagues, and neighbors. Formal and informal social support for underage children of female prisoners is even scarcer compared to other vulnerable groups.

In terms of formal social support, due to the imperfect national welfare system and the lag of the assistant system, a lack of sound legislative protection, policies, and implementation, many underage children of prisoners are in desperate need of developed family care and a supportive education system. The underage children of the prisoners should enjoy the care of their parents, the warmth of the family and the education of the school, and enjoy the happy childhood in a positive way. However, they have turned this into nothing because of sudden family changes. A child is like a grass without roots. In the corners that are not known, let the wind blow and rain. At the institutional design level, due to the existence of parents in the legal sense, it does not meet the conditions of adoption and rescue of the state welfare institutions. Because of the existence of identity labels, the government cannot enjoy the life assistance of the difficult groups [8].

In other words, the underage children of prisoners are a special vulnerable group that have gathered less attention and lack of guarantees in China. Improving their lives, improving their welfare and promoting their development are not only part of the social security system, it is also an important manifestation of state responsibility and social civilization. Due to the existence of institutional exclusion and social discrimination, it is under the influence of the public opinion that if they cannot even take care of the "good people," they would certainly not be able to deal with the "bad guys." The formal social security and support that can be obtained from prisoners and their children is minimal. In the social security system at the national and government levels, the underage children of female prisoners live in the shadow of the party and the government. Government-led formal social support barely patronizes this "vulnerable group." Based on this, the protection and care of the underage children of the female prisoners need to rely on the external resources provided by the social welfare organizations. 
In helping the sons and daughters of imprisoned women, the main role played by social welfare organizations is the "weaver" of social support networks. Charitable organizations including social work service organizations help the female prisoners' families and their children to form a community, social organization and state support, etc. through policy advocacy, resource integration, multi-party linkage as well as public participation. They gain support from emotions, identity, material, policy, etc., to restore social functions, achieve normal development, and promote social re-adjustment. Therefore, encouraging charitable organizations to participate in the protection and care of children of female prisoners is both an expedient measure and a strategic move. We can incubate professional aid agencies for underage children of prisoners in charitable sectors, volunteer organizations, nonprofit sectors, etc., and improve the professionalism and pertinence of service activities. Under the conditions where the government fails to solve problems, we can exert the power of nongovernmental organizations, integrate social public resources, call for the public to actively participate, and use the specialization and social support outside the family to "replace" the lack of functions within the familly.

It is worth mentioning that the female prisoners and their minor children are often separated from the mainstream of the society because of their sense of being labeled and deprecated. They have a strong sense of self-closure and are not easily accessible. Therefore, in view of the particularity of this group, charitable organizations should act as companions to give as much care and patience as possible, in order to solve their problems, meet their needs, and let them feel the warmth of the social family. Positive hope for progress. We must help underage children overcome their inferiority complex, transcend identity restrictions, discover their potential, correct their attitudes towards life, repair damaged socialization, and strive to achieve self-help goals and self-reliance.

For "functional replacement in the family", the author believes that the underage children should be regarded as part of a complex multidimensional relationship system, and family support should be reconstructed with "family thinking." This multidimensional relationship system has a major impact on the lives of children and is the basic source of children's support for life and relationships. Family roles such as parents, grandparents, siblings, aunts, and uncles are important components of a child's self-concept, even when specific functions are associated with these roles. They have weakened or terminated, and they still affect the thinking and behavior of underage children. Therefore, the social support system that effectively mobilizes underage children requires us to have "family thinking."

Using "family thinking" to lead the appropriate help of the underage children of prisoners, we can start from the following three aspects [9]: First, help families to "disarm," transcend interpersonal barriers, sort out emotional barriers, and help underage children mobilizes the whole family; second is to identify minor factors and successful experiences in the family to cope with challenges, overcome difficulties, and to develop new skills and approaches; and to help underage children and their families narrow their concerns so that they can both prioritize conflicting needs and focus on the issues that need to be addressed.

\section{Conclusion}

The mother's imprisonment not only means the break of the parent-child relationship, but also indicates the transformation of the family structure. The transformation of family structure is not a simple change, but a profound change in the relationship between family members' needs and interactions [10]. For underage children who serve female offenders, the mother's imprisonment not only breaks the original interaction and communication of the family, but also causes the socialized needs of the underage children to be not properly met, which increases the risk of their level of deviance. In this sense, our precise assistance to the children of prisoners needs to strengthen "family thinking," to link changes in family structure with changes in family members' interactions and changes in family members' needs, and to put these changes into the family's daily life scene.

From the perspective of social support, the underage children of prisoners are the most vulnerable groups that need to be concerned. The survival and development of this special vulnerable group will directly affect the construction of a harmonious society and the realization of a better life in China, 
and will also profoundly affect the long-term stability of the country. Regardless of their neglect and policy of laissez-faire, it will also have a negative impact on the educational reform of prisoners. We must integrate social resources, mobilize social forces, and rebuild the social support network for underage children of female offenders through "functional substitution" inside and outside the home. We can take advantage of family function substitution models such as family and friends care, community support and social assistance, and build a social support system led by the government, judicial guidance, social coordination, and multi-participation to achieve accurate bridging between government and social assistance and family and individual needs. It can effectively compensate for the fracture of parent-child relationship and the lack of family function, improve their social security, meet their growth needs, and promote their healthy socialization.

\section{References}

[1]. Liu Hongxia. The Construction and Improvement of the Submission System for Juvenile Children in Prisoners[J]. J. Law, 2016(4).

[2]. Zheng Xiaze. Investigation on the status of children of minors serving prisoners [M]. Law Press, 2006.

[3]. Li Fuqin, Sun Yubo, Rao Enming. An Empirical Study of Juvenile Offenders — A Case Study of 1807 Investigation Reports of Guangdong Province Juvenile Crime Control Institute[J]. Criminary Research, 2017 (2).

[4]. Zhu Huayan, Zhu Huajun. Field investigation on the survival status of underage children of prisoners_- Taking a county in Ningbo, Zhejiang Province as an example[J]. Youth Research, 2008(4).

[5]. Peng Huamin. Human behavior and social environment [M]. Beijing: Higher Education Press, 2011: 111.

[6]. [United States] Wago. Law and Society [M]. Renmin University of China Press, 2011.

[7]. Nie Jinghong. Social Support and Information Flow of Patients' Network Community[J]. Academic Research,2018(1).

[8]. Zhang Lijun, Jiang Yong, Yi Yijie. Investigation and Thinking on the Status of Underage Children in Prisoners__ An Empirical Analysis Based on City B in A Province[J]. Prevention of Juvenile Delinquency, 2014(5).

[9]. Yang Shanhua. Paying Attention to the Meaning of "Normal" Life_-A New Perspective on Family Sociology Research[J].Jiangsu Social Sciences,2007(5).

[10]. LIU Aiyu, YANG Shanhua. Research on Family Support of the Elderly in the Process of Social Changes[J]. Journal of Peking University(Philosophy and Social Sciences), 2000(3). 